\title{
Free and total cortisol levels are useful prognostic markers in critically ill patients: a prospective observational study
}

\section{Zita Tarjányi ${ }^{1,2}$, Gergely Montskó ${ }^{2,3}$, Péter Kenyeres ${ }^{1}$, Zsolt Márton', Roland Hágendorn' ${ }^{1}$, Erna Gulyás ${ }^{1}$, Orsolya Nemes ${ }^{1}$, László Bajnok ${ }^{1}$, Gábor L Kovács ${ }^{2,3}$ and Emese Mezösi ${ }^{1}$}

${ }^{1}$ First Department of Internal Medicine, Faculty of Medicine, University of Pécs, 13 Ifjúság, Pécs H-7624, Hungary, ${ }^{2}$ Department of Laboratory Medicine, Faculty of Medicine, ${ }^{3}$ Szentágothai Research Centre, University of Pécs, Pécs, Hungary
Correspondence should be addressed to E Mezősi

Email

emese.mezosi@aok.pte.hu

\begin{abstract}
Objective: The role of cortisol in the prediction of mortality risk in critical illness is controversial in the literature. The aim of this study was to evaluate the prognostic value of cortisol concentrations in a mixed population of critically ill patients in medical emergencies.

Design: In this prospective, observational study, measurement of total (TC) and free cortisol (FC) levels was made in the serum samples of 69 critically ill patients ( 39 males and 30 females, median age of 74 years) at admission ( $0 \mathrm{~h}$ ) and 6, 24, 48, and $96 \mathrm{~h}$ after admission.

Methods: Cortisol levels were determined using HPLC coupled high-resolution ESI-TOF mass spectrometry. The severity of disease was calculated by prognostic scores. Statistical analyses were performed using the SPSS 22.0 software.

Results: The range of TC varied between 49.9 and $8797.8 \mathrm{nmol} / \mathrm{l}, \mathrm{FC}$ between 0.4 and $759.9 \mathrm{nmol} / \mathrm{l}$. The levels of FC at $0,6,24$, and $48 \mathrm{~h}$ and TC at $0,6 \mathrm{~h}$ were significantly elevated in non-survivors and correlated with the predicted mortality. The prognostic value of these cortisol levels was comparable with the routinely used mortality scores. In predictive models, FC at 6,24 , and $48 \mathrm{~h}$ proved to be an independent determinant of mortality.

Conclusions: The predictive values of FC in the first 2 days after admission and TC within $6 \mathrm{~h}$ are comparable with the complex, routinely used mortality scores in evaluating the prognosis of critically ill patients. The cortisol response probably reflects the severity of disease.
\end{abstract}

\section{Introduction}

The strong relationship between stress and adrenocortical function was first described in 1923 by Scott (1) and then was investigated in detail by Selye in 1936 (2). Since then, it is universally accepted that stress is associated with elevated cortisol levels. Later human studies demonstrated the connection between the severity of stress and the magnitude of adrenocortical response $(3,4)$. The term 'relative adrenal insufficiency' (RAI) was introduced earlier and applied to critically ill patient populations $(5,6,7,8$, (c) 2014 European Society of Endocrinology Printed in Great Britain
$9,10,11,12,13,14)$. A serum total cortisol (TC) increase of $250 \mathrm{nmol} / \mathrm{l}$ following administration of $250 \mu \mathrm{g}$ adrenocorticotropic hormone (ACTH) was used as the diagnostic criteria of normal glucocorticoid response (7). The concept of RAI was primarily based on total serum cortisol measurements $(7,8,14,15)$. However, the total serum cortisol and the response to ACTH probably are not the most reliable indicators of adrenal function in critically ill patients. No correlation was found between total serum 
Table 1 The patients' characteristics and diagnosis at admission.

\begin{tabular}{ll} 
Age (median, interquartiles) years & $74.0(60.5 / 79.0)$ \\
Gender (female/male) & $30 / 39$ \\
Mortality rate (30-day) & $26.1 \%$ \\
Mechanical ventilation & $33.3 \%$ \\
Catecholamine treatment & $34.8 \%$ \\
APACHE II score (median, interquartiles) & $21.0(16.5 / 29.0)$ \\
SAPS II score (median, interquartiles) & $36.0(25.0 / 55.5)$ \\
Diagnosis & \\
Sepsis & 20 \\
Heart failure & 14 \\
Pulmonary embolism & 8 \\
Acute myocardial infarction & 7 \\
Respiratory failure & 6 \\
Atrial fibrillation & 3 \\
Ventricular tachycardia & 1 \\
Complete atrioventricular block & 2 \\
Drug intoxication & 3 \\
Acute kidney failure & 2 \\
Diabetic ketoacidosis & 1 \\
Gastrointestinal bleeding & 1 \\
Hypothermia & 1 \\
\hline
\end{tabular}

APACHE II, Acute Physiology and Chronic Health Evaluation II; SAPS II, Simplified Acute Physiology Score II.

cortisol and mortality in patients with septic shock $(9,16,17)$. However, others found that high TC levels were associated with increased mortality $(3,18)$. This observation debated the hypothesis of RAI. Moreover, total serum cortisol values measured by commonly used immunoassays showed a high degree of variability (19) and the classification of patients markedly differed based on the assay used (20). The random measurement of cortisol further increased the uncertainty of evaluation $(14,21)$.

About $80-90 \%$ of circulating cortisol is bound to corticosteroid-binding globulin (CBG), but only free cortisol (FC) has biological activity. Albumin binds $10-15 \%$ of cortisol with low affinity. The measurement of serum TC by immunoassay is markedly influenced by the concentrations of the CBG and albumin. In critically ill patients, there is a decrease in CBG concentration due to elevated cytokines or insulin resistance. CBG is saturated at higher cortisol levels. The concentration of FC rises exponentially at higher concentrations due to the release from $\operatorname{CBG}(7,22)$. The relationship of TC and FC becomes nonlinear in critically ill patients, so FC levels may be more informative. FC was reported being a good marker of inflammatory response in septic shock $(7,23)$. While FC levels corresponded to severity of illness, the elevation of TC did not $(17,24)$. Others confirmed that FC is a better marker of adrenal response in critical illness than TC measurement $(7,24,25)$.
The effect of cortisol is regulated at tissue level by the activity of 11- $\beta$-hydroxysteroid dehydrogenase and the real cortisol effect at cellular level is difficult to predict $(7,26)$. The concept of RAI has been further challenged by the lack of survival benefit with supranormal dose of glucocorticoid administration $(14,27)$.

Recently, a major development has been achieved in the measurement of cortisol levels by the technique of liquid chromatography coupled mass spectrometry (LC-MS) $(22,28)$. LC-MS has a greater analytical specificity in the detection of total and free serum cortisol than immunoassays and is able to separate and quantify serum TC in the presence of other steroids and metabolites $(25,26,27)$. Immunoassays carry numerous analytical problems, namely the possible cross reactivity of antibodies with similar chemical structures and antibody interferences (heterophilic antibodies or autoantibodies). No analytical errors due to cross reactivity and heterophilic antibodies are expected using LC-MS. It allows the analysis of multiple metabolites from small sample volume. However, LC-MS requires rigorous validation $(20,22)$.

Despite the obvious advantages of FC measurements by LC-MS in critically ill patients, literature data are sparse $(29,30)$. The aim of our study was to evaluate the adrenal response and the prognostic role of TC and FC concentrations with consecutive measurements by LC-MS in a mixed population of patients in critical medical conditions.

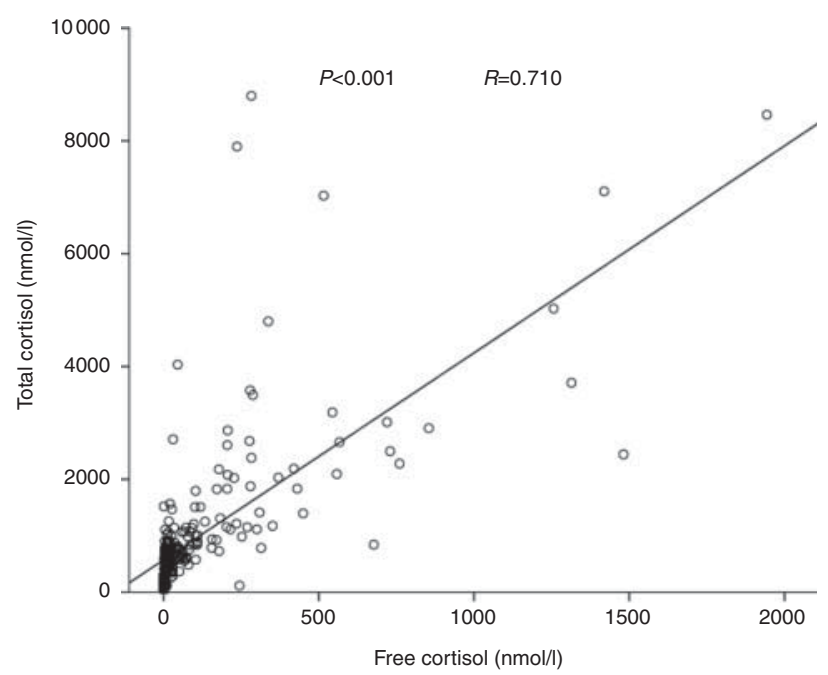

Figure 1

Correlation of free cortisol (FC) and total cortisol (TC) - Spearman correlation. 


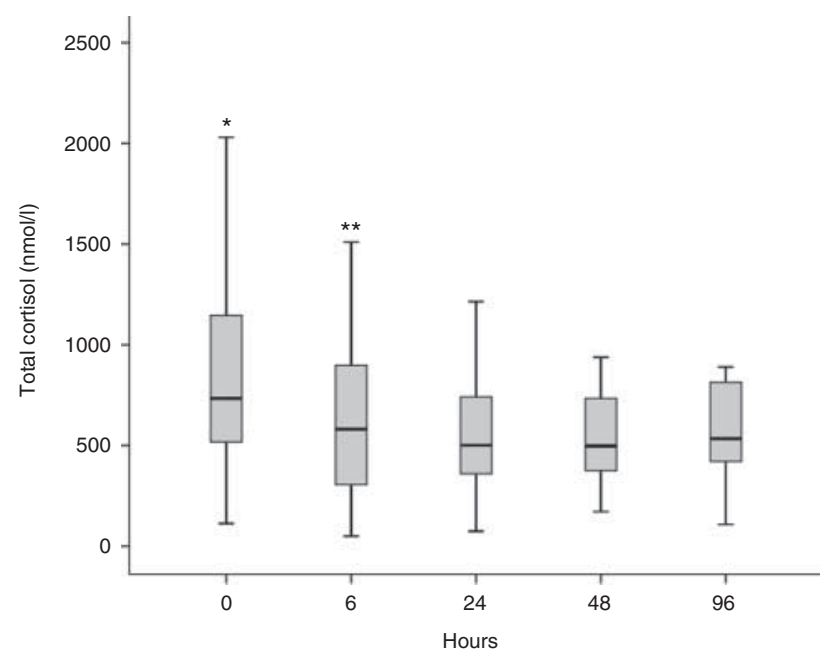

Figure 2

Total cortisol concentrations at different time points expressed as medians, interquartiles, and $95 \% \mathrm{Cls}$. *Total cortisol at admission is significantly higher than all the later medians; **total cortisol at $6 \mathrm{~h}$ is significantly higher than at $24 \mathrm{~h}$.

\section{Subjects and methods}

\section{Patients}

Our study was carried out in accordance with the ethical guidelines of the 2003 Declaration of Helsinki and we obtained the permission of Institutional Research Ethical Committee of University of Pécs. When feasible, informed consent was obtained before enrollment of conscious patients; otherwise the consent was obtained from the patients' next of kin.

The prospective, observational study was carried out in 69 non-selected patients admitted to the Intensive Care Unit of the First Department of Internal Medicine, University of Pécs, Hungary. During the enrollment period, 108 patients were treated at our intensive care unit and 79 were enrolled in the study (73\%). The patients whose informed consent was not feasible and those who died within $6 \mathrm{~h}$ were not enrolled. Ten patients were excluded from the final evaluation because of missing samples at critical time points. Gender distribution was the following: 39 males and 30 females, median age was 74 (23-87) years. The patients' characteristics and diagnosis at admission are given in Table 1 . It was a mixed population of patients in medical emergencies, no surgical or trauma patients were included (Table 1). Five patients had complete cardiopulmonary resuscitation and three patients were defibrillated before admission. Vital signs, clinical status, and routine laboratory parameters were monitored. The treatment of patients was thoroughly evaluated and blood samples disturbed by glucocorticoid treatment were excluded from the further analysis (at admission 3, at $6 \mathrm{~h} \mathrm{9,} \mathrm{at} 24 \mathrm{~h} \mathrm{7,} \mathrm{and} \mathrm{at} 48 \mathrm{~h}$ six samples). The major indication for glucocorticoid treatment was the unresponsive septic shock. None of the patients received etomidate, ketoconazole, or any other drug influencing the steroid metabolism. The severity of the diseases was scored according to the Simplified Acute Physiology Score II (SAPS II) (31) and the Acute Physiology and Chronic Health Evaluation II (APACHE II) (32) score systems.

Blood samples were taken for the measurement of FC and TC levels at admission (0 h), 6, 24, 48, and $96 \mathrm{~h}$ after admission. Blood samples were collected in anticoagulant free Vacutainer (Becton Dickinson Hungary Kft., Környe, Hungary) plastic tubes. Routine laboratory parameters were determined by the Institute of Laboratory Medicine, University of Pécs accredited according to ISO 15189. The concentrations of FC and TC were measured by HPLC coupled high-resolution electrosprayionization (ESI) timeof-flight (TOF) MS.

\section{Analysis of serum TC and FC cortisol concentrations}

After centrifugation of the collected blood samples at $2200 \boldsymbol{g}$ for $10 \mathrm{~min}$, serum was separated into plastic container tubes and was kept frozen under $-20^{\circ} \mathrm{C}$ until

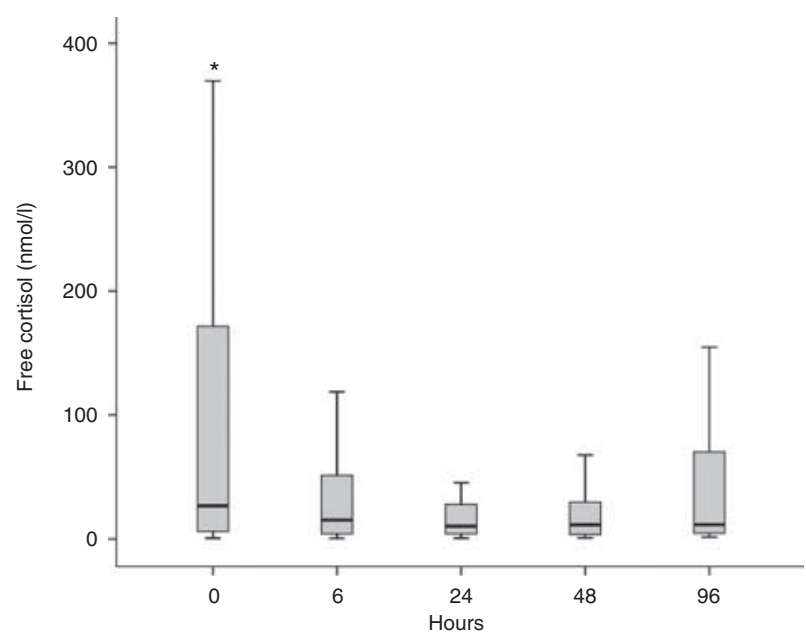

\section{Figure 3}

Free cortisol concentrations at different time points expressed as medians, interquartiles, and $95 \% \mathrm{Cls}$. *Free cortisol at admission is significantly higher than the other values. 


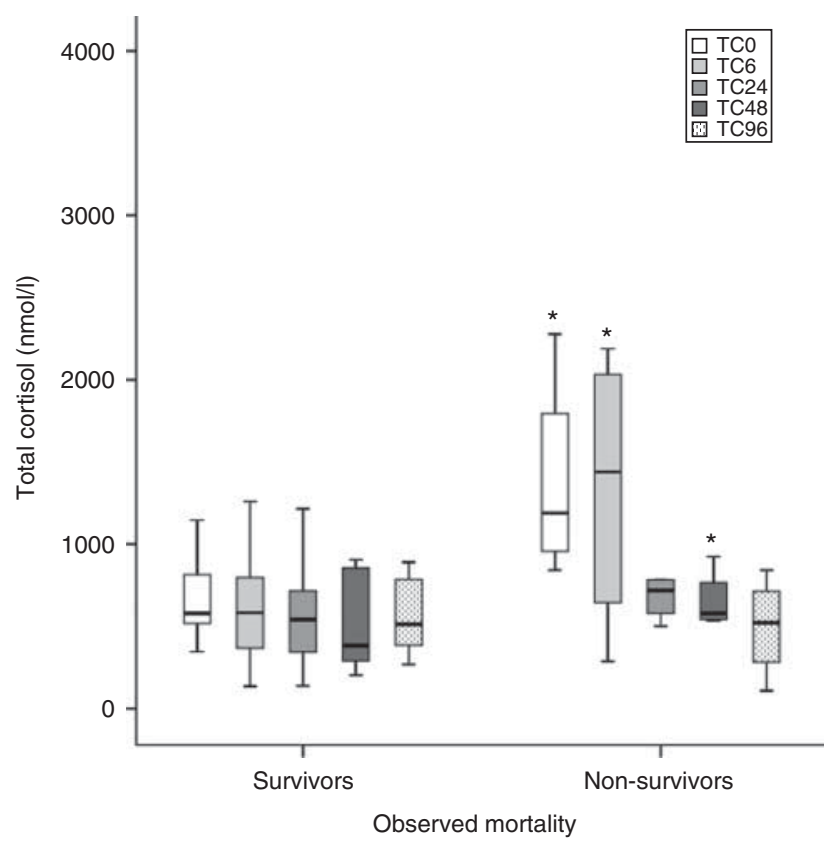

\section{Figure 4}

Total cortisol concentrations expressed as medians, interquartiles, and $95 \% \mathrm{Cls}$ in survivors $(n=51)$ and non-survivors $(n=18)$ at different time points. *Significantly elevated cortisol levels in non-survivors analyzed by Mann-Whitney $U$ test. $P$ values for TC0: 0.001, TC6: 0.029, and TC48: 0.017.

sample preparation. The sample preparation and the measurements for TC and FC analysis were carried out using HPLC-coupled high-resolution ESI-TOF MS according to the validated method described by Montskó et al. (28). Briefly, during TC analysis, $20 \mu \mathrm{l}$ of internal standard solution $(1.1 \mu \mathrm{mol} / \mathrm{l})$ was added to $100 \mu \mathrm{l}$ serum, protein was precipitated by $300 \mu \mathrm{l}$ acetonitrile, centrifuged at $14000 \boldsymbol{g}$ for $10 \mathrm{~min}$. $50 \mu \mathrm{l}$ upper phase was added to $50 \mu \mathrm{l}$ of water in an autosampler vial and vortexed. $20 \mu$ of this mixture was injected onto the HPLC column. To analyze FC, the preparation started with the mechanical removal of the protein fraction, $500 \mu \mathrm{l}$ of serum was ultrafiltrated using the $30000 \mathrm{kDa}$ molecular weight cut-off Amicon Ultra- $0.5 \mathrm{ml}$ centrifugal filters (Merck). $400 \mu \mathrm{l}$ of the ultrafiltrate was transferred to Strata-X $(60 \mathrm{mg})$ polymeric reversed-phase extraction cartridges (Phenomenex, USA). Elution was performed using $2 \times 500 \mu \mathrm{l}$ acetonitrile. The eluate was dried under vacuum, redissolved in $20 \%$ methanol in water containing $2 \mathrm{mmol} / \mathrm{l}$ ammonium acetate, and $0.05 \%$ formic acid. The injection volume was $20 \mu \mathrm{l}$. A Dionex Ultimate 3000 (Dionex, USA) analytical HPLC was used. Separation was performed on a Kinetex C8
$2.6 \mu \mathrm{m}, 2.1 \times 100 \mathrm{~mm}$ analytical column (Phenomenex). The mass spectrometer coupled to the HPLC was a Bruker micrOTOF accurate mass instrument, equipped with an ESI source operated in the positive mode. Mass spectra were collected between $\mathrm{m} / \mathrm{z} 200$ and $\mathrm{m} / \mathrm{z} 500$.

\section{Statistical analysis}

Statistical analysis was performed using SPSS 22.0 software (SPSS, Inc.). Kolmogorov-Smirnov test was used to determine the distribution of the data. All normally distributed data are presented as mean \pm s.D. The medians and interquartile ranges are reported for data that were not normally distributed. Significant results were those with $P<0.05$. TC and FC levels of survivors and non-survivors were compared using Mann-Whitney $U$ test. The relationships between non-normally distributed quantitative variables were evaluated by bivariate correlation (Spearman correlation). The diagnostic value of cortisol levels to predict mortality was determined by receiver operating characteristic (ROC) analysis. The optimal cutoff point was assessed using Youden's J statistic. KaplanMeier survival curves were created to compare the

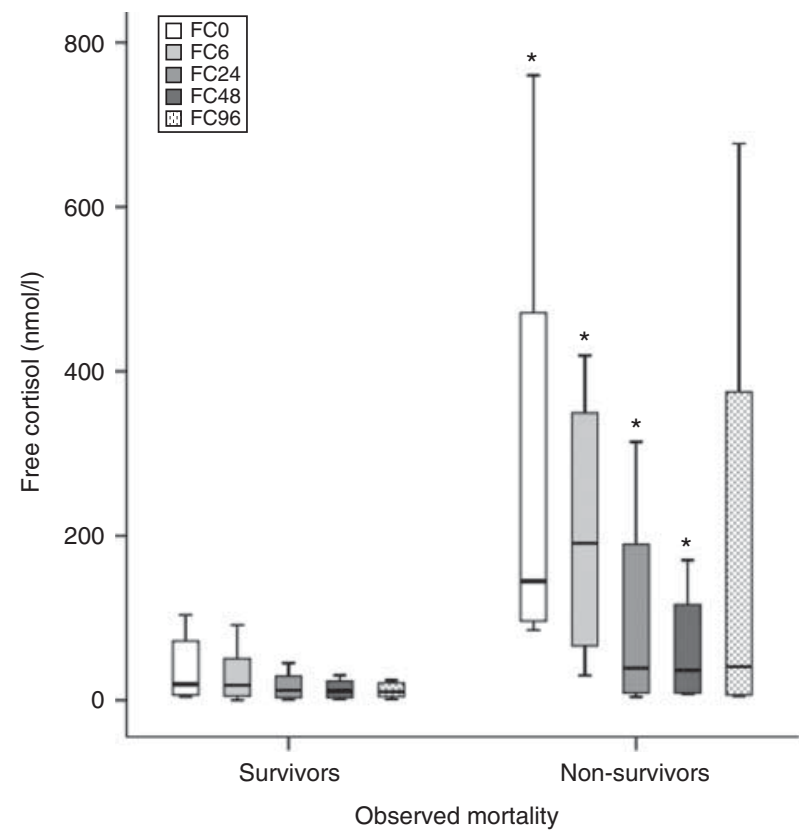

Figure 5

Free cortisol concentrations expressed as medians, interquartiles, and $95 \% \mathrm{Cls}$ in survivors $(n=51)$ and non-survivors $(n=18)$ at different time points. *Significantly elevated cortisol levels in non-survivors analyzed by Mann-Whitney $U$ test. $P$ values for FC0: <0.001, FC6: 0.001, FC24: 0.018, and FC48: 0.002 . 


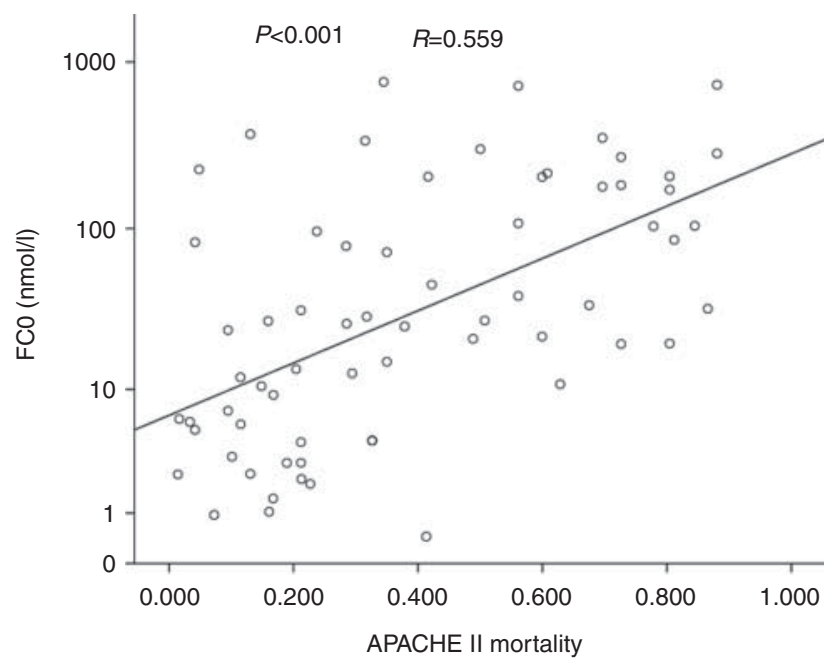

Figure 6

Relationship between free cortisol at admission (FCO) and APACHE II mortality (Spearman correlation).

mortality risk in cortisol quartiles. Independent determinants of mortality were investigated by binary logistic regression analysis using backward method.

\section{Results}

The range of TC varied between 49.9 and $8797.8 \mathrm{nmol} / \mathrm{l}$ (reference range: $138-690 \mathrm{nmol} / \mathrm{l}$ ) with a median (interquartile ranges) of 583.5 (381.5/855.8) $\mathrm{nmol} / \mathrm{l}$, FC between 0.4 and $759.9 \mathrm{nmol} / \mathrm{l}$ (reference range: $1-8 \mathrm{nmol} / \mathrm{l}$ ) with a median (interquartile ranges) of 13.4 (4.3/60.1) nmol/1. The maximal elevation of TC was 13 times and of FC was 95 times of the upper limit of reference range.

The median of TC of hydrocortisone-treated septic patients (13 samples at different time points) was $3880 \mathrm{nmol} / \mathrm{l}$, at the upper range of untreated patients. The median of FC due to hydrocortisone treatment result in supraphysiological high value, $801 \mathrm{nmol} / \mathrm{l}$. These values were not included in the statistical analyses.

The cortisol levels did not show normal distribution. TC and FC levels correlated significantly $(P<0.001$; $R=0.710$; Fig. 1). The median, interquartiles, and 95\% CI of TC and FC at different time points are shown in Figs 2 and 3. TC level at admission was significantly higher than later, and at $6 \mathrm{~h}$ was also elevated compared with later time points (Fig. 2). FC level was significantly elevated only at admission compared with later measurements (Fig. 3).

The TC and FC levels of survivors $(n=51)$ and nonsurvivors $(n=18)$ (30-day mortality) were compared.
Elevated TC was found in non-survivors at 0,6 , and $48 \mathrm{~h}$ (Fig. 4). FC level was significantly higher in non-survivors at admission and 6, 24, and $48 \mathrm{~h}$ after admission (Fig. 5). As intubation and mechanical ventilation may increase cortisol levels and may be associated with bad prognosis, the cortisol levels of ventilated and not ventilated patients were also compared at every time points. TC0 $(P=0.001)$, FC0 $(P<0.001)$, and FC6 $(P=0.001)$ were significantly higher in ventilated patients. The mortality rate was also significantly elevated in cases that required ventilation $(P<0.001)$.

The predictive role of cortisol levels was investigated in comparison with the well-accepted clinical scores, APACHE II and SAPS II mortality. The results of these correlations are shown in Fig. 6 and Table 2. FC at 0 (FC0), 6 (FC6), 24 (FC24), 48 (FC48), and $96 \mathrm{~h}$ (FC96) significantly correlated with predicted mortalities. TC at 0 (TC0) and 6 h (TC6) also correlated with mortality scores, but the correlation disappeared from TC24.

The diagnostic value of cortisol concentrations to predict mortality was next evaluated by ROC analysis (Fig. 7). The cut-off values of cortisol with optimal diagnostic accuracy are given in Table 3. A FC of $28.2 \mathrm{nmol} / 1$ at admission, for example, had $88.2 \%$ sensitivity and $67.3 \%$ specificity to predict mortality. The FC0 and TCO had higher sensitivity and lower specificity than the later values. The sensitivity and specificity of APACHE II and SAPS II mortality were similar to the diagnostic value of FC6, FC24, and FC48. The Kaplan-Meier curves showed best separation of survival at FCO analyzed in quartiles.

Table 2 Correlations of free cortisol (FC) and total cortisol (TC) levels with APACHE II and SAPS II mortalities (Spearman correlation).

\begin{tabular}{|c|c|c|c|c|}
\hline & \multicolumn{2}{|c|}{ APACHE II mortality } & \multicolumn{2}{|c|}{ SAPS II mortality } \\
\hline & $P$ value & $\begin{array}{l}\text { Correlation } \\
\text { coefficient }\end{array}$ & $P$ value & $\begin{array}{l}\text { Correlation } \\
\text { coefficient }\end{array}$ \\
\hline $\mathrm{FCO}$ & $<0.001$ & 0.559 & $<0.001$ & 0.584 \\
\hline FC6 & $<0.001$ & 0.479 & $<0.001$ & 0.474 \\
\hline FC24 & 0.011 & 0.330 & 0.029 & 0.284 \\
\hline FC48 & 0.008 & 0.421 & 0.002 & 0.480 \\
\hline FC96 & 0.029 & 0.489 & 0.030 & 0.487 \\
\hline $\mathrm{TCO}$ & $<0.001$ & 0.455 & $<0.001$ & 0.542 \\
\hline TC6 & 0.009 & 0.332 & 0.029 & 0.283 \\
\hline TC24 & 0.125 & 0.202 & 0.272 & 0.145 \\
\hline TC48 & 0.435 & 0.130 & 0.132 & 0.249 \\
\hline TC96 & 0.206 & 0.295 & 0.195 & 0.302 \\
\hline
\end{tabular}

APACHE II, AcutePhysiology and Chronic Health Evaluation II; SAPS II, Simplified Acute Physiology Score II; FCO, free cortisol at $0 \mathrm{~h}$; FC6, free cortisol at 6 h; FC24, free cortisol at 24 h; FC48, free cortisol at 48 h; FC96, free cortisol at $96 \mathrm{~h}$; TC0, total cortisol at $0 \mathrm{~h}$; TC6, total cortisol at $6 \mathrm{~h}$; TC24, total cortisol at $24 \mathrm{~h}$; TC48, total cortisol at $48 \mathrm{~h}$; TC96, total cortisol at $96 \mathrm{~h}$. 

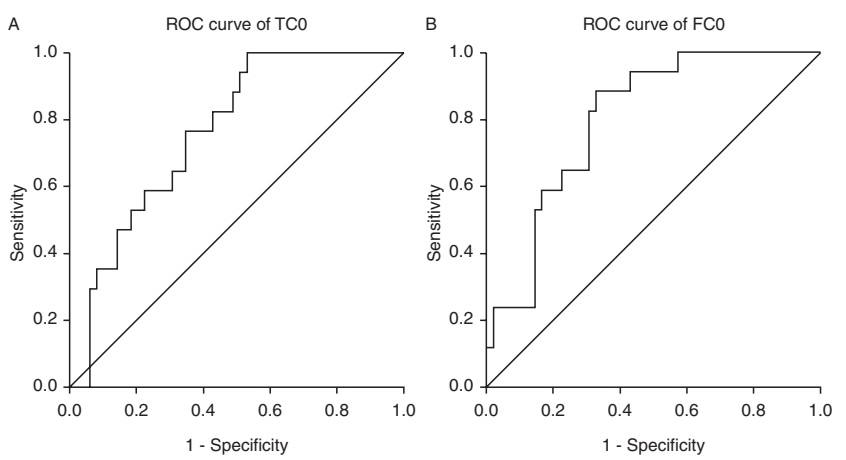

\section{Figure 7}

(A) Receiver operating characteristic (ROC) curve for serum total cortisol levels at admission (TCO). The area under the ROC curve (AUC) was 0.762. (B) ROC curve for serum free cortisol levels at admission (FCO). The AUC was 0.801.

All patients with the lowest 25\% of FC survived, while $60 \%$ of patients died in the highest quartile (>75\%) (Fig. 8). On the basis of this excellent prognostic role of cortisol levels, patients were included in mortality predicting models together with gender, age, and the complex clinical scores, APACHE II and SAPS II mortality. FC6, FC24, and FC48 turned to be independent determinants of mortality beside APACHE II and SAPS II. The sensitivity, specificity, and validity of these models were surprisingly high (Table 4). It is notable that the clinical scores created by 12 or 17 parameters and the cortisol as a single parameter are comparable in their predictive roles.

The contribution of intubation and mechanical ventilation per se to cortisol elevation is difficult to estimate. To approach this question, the role of ventilation, mortality scores, gender, age, and cortisol levels were investigated in binary logistic regression models. The need for ventilation was a very strong determinant of mortality, even stronger than the mortality scores. However, FC6, FC24, and FC48 remained an independent determinant of mortality beside ventilation. These data confirm that the intubation and ventilation themselves may, at least partly, be responsible for the significant differences in cortisol levels of survivor and non-survivor patient population.

\section{Discussion}

In this prospective observational study, TC and FC levels were determined by LC-MS in the serum of critically ill patients in medical emergencies. An extremely wide range of cortisol concentrations were found upward, exceeding the upper limit of normal by 13 times in total and 95 times in FC levels. Both TC and FC levels were elevated at admission compared with later time points. FC within 2 days and TC within $6 \mathrm{~h}$ correlated with the observed mortality. The patients with higher cortisol levels had higher risk to die. The requirement for ventilation may be partly responsible for the higher cortisol levels in non-survivors. The prognostic role of cortisol concentration was compared with the routinely used clinical mortality scores APACHE II and SAPS II, in which vital signs, clinical parameters, and laboratory values are included. The diagnostic value of cortisol concentrations to predict mortality was similar to APACHE II and SAPS II. Furthermore, FC6, FC24, and FC48 proved to be independent determinants of mortality even in prediction of models including - beyond gender and age - these complex clinical scores. Information provided by these cortisol levels as single parameters of the prognosis was similar to complex mortality scores that have been formed by 12 and 17 parameters respectively.

There are some key reports investigating the total serum cortisol levels in critically ill patients $(19,22,33)$. FC levels were reported to be measured in few papers and sparse data are available about FC determined by LC-MS $(22,25,29,30,34,35)$. Only one paper is available which demonstrates measurement of both TC and FC levels by LC-MS in critically ill patients (29). Measurement of cortisol levels using immunoassays is disturbed by many analytical errors, especially in critically ill patients. Our method of measuring cortisol levels using LC-MS was previously validated in normal subjects (28). The method

Table 3 The cut-off values of free cortisol (FC), total cortisol (TC), and mortality scores (APACHE II and SAPS II mortality) with optimal diagnostic accuracy (based on ROC analysis).

\begin{tabular}{|c|c|c|c|c|}
\hline & AUC & $\begin{array}{l}\text { Cut-off } \\
\text { value }\end{array}$ & $\begin{array}{c}\text { Sensitivity } \\
(\%)\end{array}$ & $\begin{array}{c}\text { Specificity } \\
(\%)\end{array}$ \\
\hline $\mathrm{FCO}(\mathrm{nmol} / \mathrm{l})$ & 0.801 & 28.2 & 88.2 & 67.3 \\
\hline FC6 (nmol/l) & 0.769 & 51.0 & 62.5 & 87.0 \\
\hline FC24 (nmol/l) & 0.702 & 21.1 & 56.3 & 81.4 \\
\hline FC48 (nmol/l) & 0.847 & 29.7 & 75.0 & 87.1 \\
\hline TCO (nmol/l) & 0.762 & 583.6 & 100.0 & 46.9 \\
\hline TC6 (nmol/l) & 0.694 & 886.5 & 57.1 & 82.6 \\
\hline $\begin{array}{l}\text { APACHE II } \\
\text { mortality (\%) }\end{array}$ & 0.814 & 53.4 & 77.8 & 82.4 \\
\hline $\begin{array}{l}\text { SAPS II } \\
\text { mortality (\%) }\end{array}$ & 0.843 & 54.1 & 66.7 & 88.2 \\
\hline
\end{tabular}

APACHE II, Acute Physiology and Chronic Health Evaluation II; SAPS II, Simplified Acute Physiology Score II; AUC, area under the curve; FCO, free cortisol at $0 \mathrm{~h}$; FC6, free cortisol at $6 \mathrm{~h}$; FC24, free cortisol at $24 \mathrm{~h} ; \mathrm{FC48}$, free cortisol at $48 \mathrm{~h}$; TC0, total cortisol at $0 \mathrm{~h}$; TC6, total cortisol at $6 \mathrm{~h}$; ROC, receiver operating characteristic. 


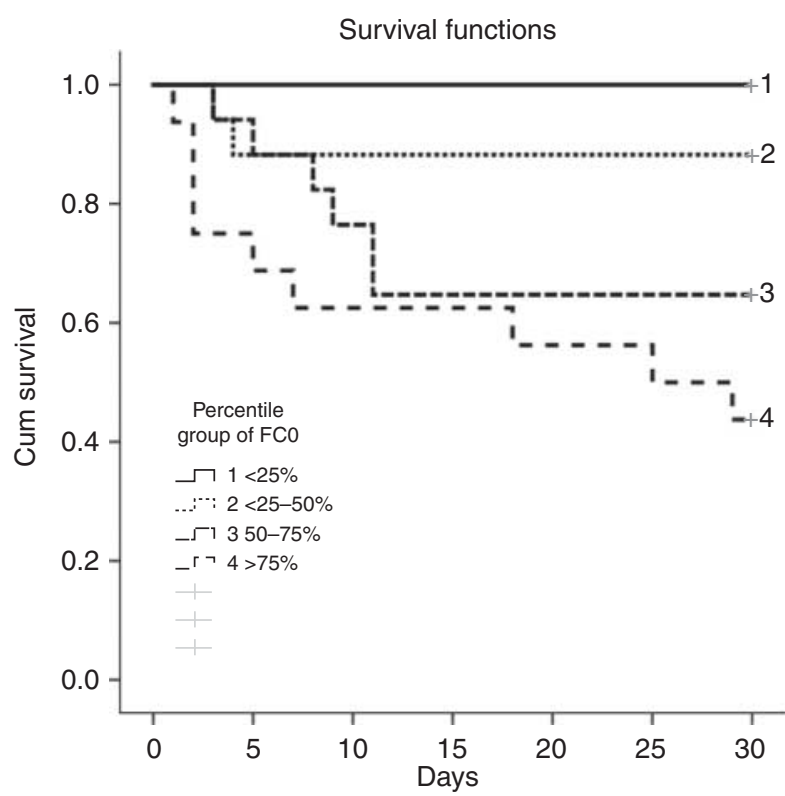

\section{Figure 8}

The Kaplan-Meier curves of survival depending on free cortisol quartiles at admission ( $F C 0$ ). Patients belonging to the lowest quartile all survived and the mortality increased with increasing free cortisol level. Free cortisol 25\%, $6.0 \mathrm{nmol} / \mathrm{l} ; 50 \%$, $26.7 \mathrm{nmol} / \mathrm{l}$; and $75 \%, 173.3 \mathrm{nmol} / \mathrm{l}$.

is capable of specific cortisol quantification in different matrices on the basis of accurate mass identification. The measurement of TC is quite simple and accurate; therefore, nowadays this method is used routinely in our Institute. The measurement of FC requires more complex sample preparation, which is a disadvantage in the everyday routine. Considering all of these factors, FC measured by LC-MS is the best method to evaluate the adrenal response in critically ill patients, but for prognostic purposes TC measured by LC-MS seems to be more available in the daily practice. Commonly, targeted mass-spectrometry analysis is carried out using triplequadrupole mass spectrometers. The method and the way of analysis are different compared with our measurement, but both assessments give similar results without the disadvantages of immunoassays (28). We believe that our results are fully transferable to cortisol levels determined by triple-quadrupole MS.

Beyond the practical consequences, our results have theoretical aspects. The cortisol response to medical emergencies seems to be proportional to the severity of illness. It can be presumed that the adrenal response is usually appropriate and maximal in life threatening conditions $(3,4,33)$. According to a new concept of cortisol homeostasis in critical illness, ACTH is not elevated, even suppressed due to the high cortisol level. It is possible that ACTH stimulation test does not result in significant cortisol elevation in those patients who already have high cortisol level. They are regarded having RAI $(9,11)$. The overproduction of cortisol is also debated. The primary cause of cortisol elevation probably is the decreased metabolism of glucocorticoids (13). The concept of RAI should be reappraised based on these new studies.

Table 4 Independent determinants of mortality in binary logistic regression analysis using six predictive models - observed mortality was used as a dependent variable.

\begin{tabular}{|c|c|c|c|c|c|c|c|}
\hline & Variables & $\begin{array}{l}\text { Independent } \\
\text { determinant ( } P \text { value) }\end{array}$ & $\begin{array}{l}\text { Cox and } \\
\text { Snell } R^{2}\end{array}$ & Nagekerke $R^{2}$ & Sensitivity & Specificity & Validity \\
\hline Model 1 & $\begin{array}{l}\text { Gender; age; } \\
\text { APACHE II } \\
\text { mortality; FC6 }\end{array}$ & $\begin{array}{l}\text { FC6 (0.058); APACHE } \\
\text { II mortality (0.006) }\end{array}$ & 0.0267 & 0.393 & 87 & 37.5 & 74.2 \\
\hline Model 2 & $\begin{array}{l}\text { Gender; age; } \\
\text { APACHE II } \\
\text { mortality; FC24 }\end{array}$ & $\begin{array}{l}\text { FC24 }(0.004) ; \\
\text { APACHE II } \\
\text { mortality }(0.001)\end{array}$ & 0.394 & 0.572 & 86 & 56.3 & 78 \\
\hline Model 3 & $\begin{array}{l}\text { Gender; age; } \\
\text { APACHE II } \\
\text { mortality; FC48 }\end{array}$ & $\begin{array}{l}\text { FC48 (0.021) Age } \\
\quad(0.056)\end{array}$ & 0.419 & 0.419 & 96.8 & 62.5 & 89.7 \\
\hline Model 4 & $\begin{array}{l}\text { Gender; age; SAPS II } \\
\text { mortality; FC6 }\end{array}$ & $\begin{array}{l}\text { FC6 }(0.024) ; \text { SAPS II } \\
\text { mortality }(0.001)\end{array}$ & 0.331 & 0.486 & 89.1 & 56.3 & 80.6 \\
\hline Model 5 & $\begin{array}{l}\text { Gender; age; SAPS II } \\
\text { mortality; FC24 }\end{array}$ & $\begin{array}{l}\text { FC24 }(0.003) ; \text { SAPS II } \\
\text { mortality } \\
(P<0.001)\end{array}$ & 0.477 & 0.692 & 90.7 & 81.3 & 88.1 \\
\hline Model 6 & $\begin{array}{l}\text { Gender; age; SAPS II } \\
\text { mortality; FC48 }\end{array}$ & $\begin{array}{c}\text { FC48 }(0.023) ; \text { SAPS II } \\
\text { mortality }(0.051)\end{array}$ & 0.470 & 0.738 & 96.8 & 75.0 & 92.3 \\
\hline
\end{tabular}

APACHE II, Acute Physiology and Chronic Health Evaluation II; SAPS II, Simplified Acute Physiology Score II; FC6, free cortisol at 6 h; FC24, free cortisol at 24 h; FC48, free cortisol at $48 \mathrm{~h}$. 
Further investigations are essential in patients with unresponsive septic shock for which the high-dose hydrocortisone treatment is a routine therapy $(12,33,36)$.

The limitation of our study has been the relatively small patient population due to multiple cortisol measurements that restricted the potential size of study. However, the investigated prognostic markers including cortisol had high statistical power. Although the heterogeneity of underlying diseases might be regarded as another potential weakness on the investigation, severity of various diseases were similar, therefore the same prognostic models could be applied to all of them. Only medical intensive care unit patients have been studied. In the future, the evaluation may be extended to surgical and trauma patients.

In conclusion, the $\mathrm{TC}$ and $\mathrm{FC}$ concentrations in critically ill patients varied in a very wide range that the highest TC exceeded 13 times and FC 95 times the upper limit of reference range. Both TC and FC levels measured by LC-MS were useful prognostic markers: patients with higher cortisol levels had higher mortality risk. FC had an advantage compared with $\mathrm{TC}$, being a predictor of mortality in the first 2 days after admission. FC at 6, 24, and $48 \mathrm{~h}$ proved to be an independent predictor of mortality in prognostic models even including the SAPS II and APACHE II mortality scores. Cortisol levels in critical illness probably reflect the severity of disease.

\section{Declaration of interest}

The authors declare that there is no conflict of interest that could be perceived as prejudicing the impartiality of the research reported.

\section{Funding}

This work was supported by research grants OTKA 78480 and SROP-4.2.1. B-10/2/KONV-2010-0002.

\section{Author contribution statement}

E Mezösi conceived of the study, analyzed data, and wrote the manuscript. G Montskó developed the method of measurement using HPLC-MS/MS. G Montskó and Z Tarjányi carried out the hormone level measurements. E Mezősi, P Kenyeres, and Z Tarjányi performed the statistical analysis. E Gulyás, O Nemes, Z Márton, R Hágendorn, and Z Tarjányi collected data and assisted in patient recruitment. L Bajnok and G L Kovács participated in the design and coordination of the study.

\section{References}

1 Scott WJ. The influence of the adrenal glands on resistance: I. The susceptibility of adrenalectomized rats to morphine. Journal of Experimental Medicine 192338 543-560. (doi:10.1084/jem.38.5.543)
2 Selye H. A syndrome produced by diverse nocuous agents. 1936. Journal of Neuropsychiatry and Clinical Neurosciences 199810 230-231.

3 Melby JC \& Spink WW. Comparative studies on adrenal cortical function and cortisol metabolism in healthy adults and in patients with shock due to infection. Journal of Clinical Investigation 195837 1791-1798. (doi:10.1172/JCI103772)

4 Chernow B, Alexander HR, Smallridge RC, Thompson WR, Cook D, Beardsley D, Fink MP, Lake CR \& Fletcher JR. Hormonal responses to graded surgical stress. Archives of Internal Medicine 1987147 1273-1278. (doi:10.1001/archinte.1987.00370070087013)

5 Annane D, Sébille V, Troché G, Raphaël JC, Gajdos P \& Bellissant E. A 3-level prognostic classification in septic shock based on cortisol levels and cortisol response to corticotropin. Journal of the American Medical Association 200023 1038-1045. (doi:10.1001/jama.283.8.1038)

6 Beishuizen A, Vermes I, Hylkema BS \& Haanen C. Relative eosinophilia and functional adrenal insufficiency in critically ill patients. Lancet 1999353 1675-1676. (doi:10.1016/S0140-6736(99)01346-X)

7 Beishuizen A \& Thijs LG. Relative adrenal failure in intensive care: an identifiable problem requiring treatment? Best Practice \& Research Clinical Endocrinology \& Metabolism 200115 513-531. (doi:10.1053/ beem.2001.0167)

8 Cooper MS \& Stewart PM. Corticosteroid insufficiency in acutely ill patients. New England Journal of Medicine 2003348 727-734. (doi:10.1056/NEJMra020529)

9 Dimopoulou I, Stamoulis K, Ilias I, Tzanela M, Lyberopoulos P, Orfanos S, Armaganidis A, Theodorakopoulou M \& Tsagarakis S. A prospective study on adrenal cortex responses and outcome prediction in acute critical illness: results from a large cohort of 203 mixed ICU patients. Intensive Care Medicine 200733 2116-2121. (doi:10.1007/ s00134-007-0790-0)

10 Marik PE, Pastores SM, Annane D, Meduri GU, Sprung CL, Arlt W, Keh D, Briegel J, Beishuizen A, Dimopoulou I et al. Recommendations for the diagnosis and management of corticosteroid insufficiency in critically ill adult patients: consensus statements from an international task force by the American College of Critical Care Medicine. Critical Care Medicine 200836 1937-1949. (doi:10.1097/CCM. Ob013e31817603ba)

11 Knapp PE, Arum SM \& Melby JC. Relative adrenal insufficiency in critical illness: a review of the evidence. Current Opinion in Endocrinology and Diabetes 200411 147-152. (doi:10.1097/01.med.0000136121. 99139.00)

12 Toma A, Stone A, Green RS \& Gray S. Steroids for patients in septic shock: the results of the CORTICUS trial. Canadian Journal of Emergency Medicine 201113 273-276.

13 Van den Berghe G. Endocrine evaluation of patients with critical illness. Endocrinology and Metabolism Clinics of North America 200332 385-410. (doi:10.1016/S0889-8529(03)00005-7)

14 Venkatesh B \& Cohen J. Adrenocortical (dys)function in septic shock a sick euadrenal state. Best Practice \& Research. Clinical Endocrinology \& Metabolism 201125 719-733. (doi:10.1016/j.beem.2011.04.007)

15 Rothwell PM, Udwadia ZF \& Lawler PG. Cortisol response to corticotropin and survival in septic shock. Lancet 1991337 582-583. (doi:10.1016/0140-6736(91)91641-7)

16 Dickstein G. On the term "relative adrenal insufficiency"- or what do we really measure with adrenal stimulation tests? Journal of Clinical Endocrinology and Metabolism 200590 4973-4974. (doi:10.1210/jc. 2005-1196)

17 Rady MY, Johnson DJ, Patel B, Larson J \& Helmers R. Cortisol levels and corticosteroid administration fail to predict mortality in critical illness: the confounding effects of organ dysfunction and sex. Archives of Surgery 2005140 661-668. (doi:10.1001/archsurg.140.7.661)

18 Sam S, Corbridge TC, Mokhlesi B, Comellas AP \& Molitch ME. Cortisol levels and mortality in severe sepsis. Clinical Endocrinology 200460 29-35. (doi:10.1111/j.1365-2265.2004.01923.x)

19 Cohen J, Ward G \& Prins J. Variability of cortisol assays can confound the diagnosis of adrenal insufficiency in the critically ill population. 
Intensive Care Medicine 200632 1901-1905. (doi:10.1007/s00134-0060389-x)

20 Briegel J, Sprung CL \& Annane D. Multicenter comparison of cortisol as measured by different methods in samples of patients with septic shock. Intensive Care Medicine 200935 2151-2156. (doi:10.1007/ s00134-009-1627-9)

21 Venkatesh B, Mortimer RH \& Couchman B. Evaluation of random plasma cortisol and the low dose corticotropin test as indicators of adrenal secretory capacity in critically ill patients: a prospective study. Anaesthesia and Intensive Care 200533 201-209.

22 Clark PM \& Gordon K. Challenges for the endocrine laboratory in critical illness. Best Practice \& Research. Clinical Endocrinology \& Metabolism 201125 847-859. (doi:10.1016/j.beem.2011.04.010)

23 Beishuizen A, Thijs L \& Vermes I. Patterns of corticosteroid-binding globulin and the free cortisol index during septic shock and multitrauma. Intensive Care Medicine 200127 1584-1591. (doi:10.1007/ s001340101073)

24 Hamrahian AH, Oseni TS \& Arafah BM. Measurements of serum free cortisol in critically ill patients. New England Journal of Medicine 2004 350 1629-1638. (doi:10.1056/NEJMoa020266)

25 Burt MG, Mangelsdorf BL, Rogers A, Ho JT, Lewis JG, Inder WJ \& Doogue MP. Free and total plasma cortisol measured by immunoassay and mass spectrometry following $\mathrm{ACTH}_{1-24}$ stimulation in the assessment of pituitary patients. Journal of Clinical Endocrinology and Metabolism 201398 1883-1890. (doi:10.1210/jc.2012-3576)

26 Gatti R, Antonelli G, Prearo M, Spinella P, Cappellin E \& De Palo EF. Cortisol assays and diagnostic laboratory procedures in human biological fluids. Clinical Biochemistry 200942 1205-1217. (doi:10.1016/j.clinbiochem.2009.04.011)

27 Oppert M, Reinicke A, Gräf KJ, Barckow D, Frei U \& Eckardt KU. Plasma cortisol levels before and during "low-dose" hydrocortisone therapy and their relationship to hemodynamic improvement in patients with septic shock. Intensive Care Medicine 200026 1747-1755. (doi:10.1007/ s001340000685)

28 Montskó G, Tarjányi Z, Mezősi E \& Kovács GL. A validated method for measurement of serum total, serum free, and salivary cortisol, using high-performance liquid chromatography coupled with highresolution ESI-TOF mass spectrometry. Analytical and Bioanalytical Chemistry 2014406 2333-2341. (doi:10.1007/s00216-014-7642-x)

29 Cohen J, Smith ML, Deans RV, Pretorius CJ, Ungerer JP, Tan T, Jones M $\&$ Venkatesh B. Serial changes in plasma total cortisol, plasma free cortisol, and tissue cortisol activity in patients with septic shock: an observational study. Shock 201237 28-33. (doi:10.1097/SHK. Ob013e318239b809)

30 Vassiliadi DA, Ilias I, Tzanela M, Nikitas N, Theodorakopoulou M, Kopterides P, Maniatis N, Diamantakis A, Orfanos SE, Perogamvros I et al. Interstitial cortisol obtained by microdialysis in mechanically ventilated septic patients: correlations with total and free serum cortisol. Journal of Critical Care 201328 158-165. (doi:10.1016/j.jcrc. 2012.07.008)

31 Le Gall JR, Lemeshow S \& Saulnier F. A new Simplified Acute Physiology Score (SAPS II) based on a European/North American multicenter study. Journal of the American Medical Association 1993270 2957-2963. (doi:10.1001/jama.1993.03510240069035)

32 Knaus WA, Draper EA, Wagner DP \& Zimmerman JE. APACHE II: a severity of disease classification system. Critical Care Medicine 198513 818-829. (doi:10.1097/00003246-198510000-00009)

33 Arafah BM. Hypothalamic pituitary adrenal function during critical illness: limitations of current assessment methods. Journal of Clinical Endocrinology and Metabolism 200691 3725-3745. (doi:10.1210/jc. 2006-0674)

34 Shackleton C. Clinical steroid mass spectrometry: a 45-year history culminating in HPLC-MS/MS becoming an essential tool for patient diagnosis. Journal of Steroid Biochemistry and Molecular Biology 2010121 481-490. (doi:10.1016/j.jsbmb.2010.02.017)

35 Cohen J, Venkatesh B \& Tan T. Comparison of the diagnostic accuracy of measured and calculated free cortisol in acutely ill patients using the Coolens equation. Critical Care and Resuscitation 201315 39-41.

36 Sprung CL, Annane D, Keh D, Moreno R, Singer M, Freivogel K, Weiss YG, Benbenishty J, Kalenka A, Forst $\mathrm{H}$ et al. Hydrocortisone therapy for patients with septic shock. New England Journal of Medicine 2008358 111-124. (doi:10.1056/NEJMoa071366)

Received 10 July 2014

Revised version received 4 September 2014

Accepted 29 September 2014 